\title{
Biotechnology as a therapeutic strategy
}

\section{La Biotecnología como estrategia terapéutica}

\author{
Gloria M. Vásquez
}

Grupo de Inmunología Celular e Inmunogenética, Instituto de Investigaciones Médicas, Facultad de Medicina, Universidad de Antioquia, Medellín, Colombia

The production of recombinant proteins began in 1980, and useful compounds, such as human insulins, were generated. This biotechnological strategy facilitated the treatment of diabetes mellitus while at the same time decreasing intolerance reactions caused by the use of animal-derived insulins.

The use of recombinant proteins continued growing, and, currently, erythropoietin and growth factors are available, among others.

Furthermore, the discovery that previously sensitized animal serum for the treatment of diphtheria was possible and effective, suggested that the antibodies it contained were a therapeutic strategy.

The previous observation was followed by the development of the hybridoma technique, which Kohler and Milsten, winners of the 1984 Nobel Prize, had been working on since the 70s. Their work led to the generation of monoclonal antibodies, which, in addition to their multiple applications in experimental and diagnostic processes, are used as treatment strategies.

A murine antibody directed against the human $\mathrm{CD} 3$ molecule, expressed by the $\mathrm{T}$ lymphocytes, was used for the first time in 1983, inducing a depletion of these cells.

DOI of original article:

http://dx.doi.org/10.1016/j.rccar.2016.09.002

E-mail addresses: glomavas@gmail.com, gloria.vasquez@udea.edu.co
This antibody, the first one used in humans for therapeutic purposes in the management of kidney transplant rejection, was considered to be an effective strategy for many years. In 1991, the successful use of this antibody for the first time in our country, for the treatment of a patient with kidney rejection, was published in the Revista Colombiana de Cirugía [Colombian Journal of Surgery].

After using murine-derived antibodies for the management of acute conditions, and having demonstrated their effectiveness and safety, the possibility arose of implementing this type of strategies for chronic conditions. The observation of so-called "serum sicknes̈s in which the immune system recognizes the foreign proteins contained in the applied serum and which induce an immune response, generate concern regarding the long-term use of these antibodies. This immune response leads to serum inactivation or to the formation of immune complexes which may precipitate in the organs and induce cellular and complement activation and subsequent tissue lesions. Due to this, biotechnological strategies were developed which would reduce the amount of foreign protein. The strategy was the use of genetic engineering and the generation of antibodies which would reduce the content of murine proteins. These antibodies were formed by variable murine-derived regions obtained from mice sensitized with the antigen of interest, and constant fractions of the antibody which came from human genes. In light of this composition, these antibodies were called chimeric. 
Based on this technology, treatments were developed which are in use today, such as rituximab, directed against a $B$ lymphocyte protein (CD20), and which induces a depletion of these lymphocytes, indicated in the treatment of lymphomas and rheumatoid arthritis; or baxiliximab, directed against the CD25 molecule of the T lymphocytes, and indicated in kidney transplant rejection.

The persistence of a murine component for use in chronic diseases was still a challenge due to the possibility that these proteins might continue to be immunogenic. The technological advances continued, in order to reduce the murine component to its minimal expression, and humanized antibodies were obtained such as tocilizumab, indicated in rheumatoid arthritis, or daclizumab, useful in the treatment of multiple sclerosis.

New technologies, such as "phage libraries, which allow the generation of proteins with human-derived sequences which are specific for the recognition of certain antigens, are currently used for generating completely human monoclonal antibodies, with demonstrated effectiveness in multiple chronic illnesses; among these is adalimumab for rheumatoid arthritis, or ustekinumab for psoriasis.

However, biotechnology has not just stayed in the field of monoclonal antibodies, the generation of fusion proteins, the frequent use of recombinant proteins, and the generation of vaccines with more selective antigens and more efficient adjuvants which provide a longer-lasting immunological memory; rather, it has taken the lead as part of our daily therapeutic strategies.

In cardiology, biotechnology has also been used for many years, and covers various aspects of diseases: antidotes such as digibind, a sheep-derived Fab antibody fraction, indicated in digoxin intoxication, and idarucizumab, a humanized antibody, whose Fab fraction combines with dabigatran and reverts its effect from the first minute of infusion. In addition, abciximab has been used to avoid thrombotic complications. Abciximab is a chimeric monoclonal antibody directed against the Ilb/Illa platelet glycoprotein, which is useful in the prevention of thrombotic complications in percutaneous coronary interventions for acute myocardial infarctions.

In the management of heart transplants, as in kidney transplants, murine, chimeric and humanized antibodies have been used, such as muromonab, basiliximab, and daclizumab.
This type of medications has also been used in more specific events such as the blocking of membrane attack complex formation (C5b-9) by the antibody directed against the C5 complement protein, with the aim to diminish the apoptosis that occurs during acute myocardial infarction with ST elevation, or in heart surgery, especially in coronary revascularization, in order to minimize cellular damage due to ischemia and reperfusion.

More recently, the management of hyperlipidemia has been proposed, specifically for management of LDL elevations, with biotechnological medications directed against the proprotein convertase subtilisin/kexin type 9 (PCSK9), such as evolocumab (AMG 145), alirocumab and bococizumab.

New molecules would be discovered in the pathogenesis of acute and chronic illnesses, new cells will be described with determinant roles in some of them, and this will make them possible therapeutic targets to be managed with a biotechnological approach.

The advances have allowed biotechnological products to be ever safer, more effective and economical, and have led to a greater number of diseases and patients being treated with these medications. Thus, the importance of knowing them, and understanding their origin and their physiology in order to feel more secure in having them as a therapeutic option.

\section{Recommended references}

Machado NP, Téllez GA, Castaño JC. Anticuerpos monoclonales: desarrollo físico y perspectivas terapéuticas. Infectio. 2006;10:186-97.

Quintero AG, Patiño MO, Latiff A, Ramírez J, García CF. Anticuerpos monoclonales OKT3. Su uso en el trasplante renal cadavérico. Primera Experiencia en Colombia. Rev Col Cirugía. 1991;6:18-20.

Foltz IN, Karow M, Wasserman MS. Evolution and emergence of therapeutic monoclonal antibodies: what cardiologists need to know. Circulation. 2013;127:2222-30.

Beck A, Wurch T, Bailly C, Corvaia N. Strategies and challenges for the next generation of therapeutic antibodies. Nat Rev Immunol. 2010;10:345-52.

Tabrizi M, Funelas C, Suria H. Application of quantitative pharmacology in development of therapeutic monoclonal antibodies. AAPS J. 2010;12:592-601.

Adams-Sánchez CD, Tobón-García GJ. Terapia con anticuerpos monoclonales en Cardiología y Medicina Interna. Rev Colomb Cardiol. 2016;23:293-300. 